\title{
COVID-19 and Spanish Flu Pandemics - Similarities and Differences
}

\author{
Goran Belojevic* \\ Institute of Hygiene and Medical Ecology, Faculty of Medicine, University of Belgrade, Dr Subotica starijeg 8, 11000 Belgrade, Serbia
}

${ }^{\star}$ Corresponding author: Goran Belojevic, Institute of Hygiene and Medical Ecology, Faculty of Medicine, University of Belgrade, Dr Subotica starijeg 8, 11000 Belgrade, Serbia; Tel: +381 113612 762; Fax: +381 112682 852; Cell: +381 63 369674; E-mail: goran.belojevic@med.bg.ac.rs

Received: November 19, 2020; Accepted: November 25, 2020; Published: November 30, 2020

\section{Summary}

The aim of this paper is to analyze the similarities and differences between the COVID-19 and Spanish Flu and to predict the course of the COVID-19 pandemic. We carried out a literature search of publications in English in PubMed database with the following keywords: "COVID-19" and "Spanish Flu". We found the following similarities between Spanish Flu and the COVID-19: the new agent, affected the whole world, similar reproductive numbers, similar case fatality rates, spreading through droplets or by touching contaminated surfaces, similar symptoms and signs, and middle-age as a dominant one among cases. The main differences are the causal agents, Spanish Flu started in the USA, while the COVID-19 started in China, currently, the number of cases and deaths was several times higher in Spanish Flu than in the COVID-19, and the incubation period is much longer in the COVID-19 (up to 28 days) than in Spanish Flu (1-2 days). Based on the experiences from Spanish Flu it may be expected that the COVID-19 pandemic may last until the end of 2021.

The current COVID-19 pandemic is causing tectonic health, economic, political and safety disturbances in the world. This is an unusual global epidemiologic event that frustrates all the world nations and health professionals because of constantly increasing number of cases and deaths and the absence of efficient treatment or vaccine [1]. To predict the course of this pandemic it may be helpful to analyze a similar previous pandemic. The pandemic that mostly resembles the COVID-19 is the Spanish Flu which devastated the world during 19181920. The Spanish Flu was the single most deadly epidemic in human history with around 500 million cases and 50 million deaths [2]. The main contextual difference between these two pandemics is that the Spanish Flu started during the First World War, while the COVID-19 has begun in global peace. Of course, there is also a hundred years time difference between the Spanish Flu and the COVID-19 that has been fulfilled with research and development in medicine.

The aim of this study is to compare the Spanish Flu and the COVID-19 pandemics using literature research. We expect that this comparison may be helpful in predicting the course of the COVID-19 pandemic. We carried out a literature search of the publications in English in PubMed database with the following keywords: "COVID-19" and "Spanish Flu". A comparative analysis used usual epidemiological key parameters. The comparative data concerning the Spanish Flu and the COVID-19 are presented in Table 1.

The main similarities are that the agent was new, the affected region was the whole world, the reproductive numbers were similar, mean case fatality rates were similar, fast spreading through droplets or by touching contaminated surfaces, major symptoms and signs were similar, and dominant age among cases was middle-aged.

The main differences are that the Spanish Flu was caused with the H1N1 influenza virus while the COVID19 is caused with the SARS CoV-2 virus, the Spanish Flu started in the USA, while the COVID-19 started in China, currently the number of cases and deaths was several times higher in Spanish Flu compared to the COVID-19, the incubation period is much longer in the COVID-19 (up to 28 days) than in the Spanish Flu (1-2 days), the specific symptoms are purple face in the Spanish Flu and anosmia, ageusia, hypoacusis and disseminated intravascular coagulation in the COVID-19, in the Spanish Flu the case fatality rate was highest among young adults while in the COVID-19 it is among very old people and immunocompromised patients, the highest case fatality rate in the Spanish Flu was 25\% and much lower in the COVID-19 (11\%), in the Spanish Flu the public information about the pandemic was censored due to war, while in the COVID-19 it is uncensored; finally, public health measures in terms of quarantine, isolation, and social distancing and protective masks were limited to the most developed countries in the Spanish Flu while in the COVID19 they are massive.

Spanish Flu is a wrong name for the 1918 pandemic. It did not start in Spain. Spain was the first country to inform about the epidemic because it was neutral in the war conflict. In the war affected countries like France and Britain the information about the epidemic was hidden. In Spain the disease was named French Flu [3]. The index case of Spanish Flu was in a military camp and more probably in Kansas (USA) than in France [2], while in Covid-19 it was at an animal market in Wuhan, China (1). In Spanish Flu there were four waves in the period between the spring 2018 and spring 2020. The first wave is not universally regarded as Spanish Flu because it was very similar to a seasonal influenza [4]. However, in August 2016, a disastrous second wave of the Spanish Flu started and it lasted six weeks [5]. The analysis of permafrost-frozen corpses from 1918 showed that Spanish Flu had been caused by a new strain of the H1N1 influenza virus A, and the victims usually died of secondary bacterial pneumonia due to yet undiscovered antibiotics [6]. COVID-19 
Table 1: Comparative data concerning Spanish Flu and COVID-19.

\begin{tabular}{|c|c|c|c|}
\hline Parameter & Spanish Flu & Covid19 & Reference \\
\hline Time of Onset & 4 March 1918 & 31 December 2019 & {$[1,2]$} \\
\hline Place of Onset & Military Campus, Kansas, USA & Sea-food and animal market, Wuhan, China & {$[1,2]$} \\
\hline Agent & $\mathrm{H} 1 \mathrm{~N} 1$ virus & SARS CoV-2 virus & {$[6,7]$} \\
\hline Agent Novelty & New & New & {$[6,7]$} \\
\hline Duration & Two years 1918-1920 & Currently ten months & {$[1,2,5]$} \\
\hline Cases & 500 million & Currently around 44 million (28.10.2020) & {$[1,14]$} \\
\hline Deaths & 50 million & Currently around 1,2 million (21.10.2020) & {$[1,14]$} \\
\hline Affected Region & World & World & {$[1,2]$} \\
\hline Reproductive Number (Median) & 1.8 & $2.5-2.9$ & {$[8,9]$} \\
\hline Case Fatality Rate & $2.5 \%$ (up to $25 \%$ ) & $3,4 \%$ (up to $11 \%$ ) & {$[10,11]$} \\
\hline Incubation period & $1-2$ days & $0-28$ days & {$[11,12]$} \\
\hline Common Symptoms and Signs & $\begin{array}{c}\text { Fever, Dry Cough, Weakness, Hypoxia, Dyspnea, Cytokine Storm, } \\
\text { Acute Respiratory Distress Syndrome, Pneumonia }\end{array}$ & Ibidem & {$[1,2]$} \\
\hline Specific Symptoms and Signs & Purple color of the face & $\begin{array}{c}\text { Anosmia, Ageusia, Hypoacusis, Diarrhoea, Disseminated } \\
\text { Intravascular Coagulation }\end{array}$ & {$[1,2]$} \\
\hline Treatment & $\begin{array}{l}\text { Symptomatic Aspirin, Quinine, Arsenics, } \\
\text { Digitalis, Strychnine, Epsom Salts, Castor Oil and Iodine }\end{array}$ & $\begin{array}{l}\text { Symptomatic Remdesivir, Lopinavir, Hydroxychloroquine, } \\
\text { Azithromycin, Dexamethason, Heparine }\end{array}$ & {$[1,2]$} \\
\hline Vaccine & No & Not yet & {$[1,2]$} \\
\hline Way of Spreading & Person to person via droplets or touching contaminated surfaces & Ibidem & {$[1,2]$} \\
\hline Dominant Age of Cases & W shape (Very Young, Middle Aged, Yery Old) & Middle Aged & {$[1,2]$} \\
\hline Categories under High Mortality Risk & Young Adults ( $18-40$ years) & Very Old, Chronic Diseases, Immuno-Compromised Patients) & {$[1,2]$} \\
\hline Pandemic Course & Four Waves & Currently Three Waves & {$[1,2]$} \\
\hline Public Information & Mainly Censored & Mainly Uncensored & {$[1,2]$} \\
\hline Public Health Measures & Limited & Massive & {$[13.14]$} \\
\hline
\end{tabular}

was caused by a novel strain of RNA coronavirus with about $80 \%$ genetic similarity with the SARS CoV and the Middle East Respiratory Syndrome Coronavirus [7]. The median reproduction number (R0) or the number of persons an affected person can infect for the Spanish Flu was 1.80 [8] while the current data concerning COVID-19 suggest that $\mathrm{R} 0$ is around 2.5-2.9 [9].

The mean case-fatality rate in the Spanish Flu was about $2.5 \%$, but in some countries it rose to $25 \%$ [10]. The mean case fatality rate of the COVID-19 is about 3, $4 \%$ and in Italy it has increased to $11 \%$ (11). A median incubation period in Spanish Flu was 1-2 days [11]. The median incubation period of the COVID-19 is between 2 and 12 days (median 5.1 days) and the full range is from 0-28 days [12]. The Spanish Flu was characterized with fever, dyspnea, dry cough, weakness and hypoxia [2]. The all-too-common sequelae of the Spanish Flu were hypoxia and death, with vivid descriptions of the purple color of the skin of those whose lungs could no longer supply their bodies with vital oxygen. That is why a common name for the Spanish Flu was "purple death".

The main symptoms of the COVID-19 are fever, cough, fatigue, slight dyspnoea, headache, conjunctivitis and diarrhea. The specific feature of the COVID19 is a neurotropism of SARS CoV-2 which may invade the olfactory nerve, acoustic nerve or sensory fibres of the vagus nerve [1]. The Spanish Flu was treated with Aspirin, Quinine, Arsenics, Digitalis, Strychnine, Epsom Salts, Castor Oil and Iodine.
Similarly, there is no registered medicine for the COVID-19. The patients are treated with Remdesivir, Lopinavir, Hydroxychloroquine, Azithromycin, Dexamethason and Heparin [2]. In order to avoid panic among the people during the Spanish Flu many local authorities used to hide statistics about the affected and deaths [13]. Contrary to the Spanish Flu, in the COVID-19 the world statistics on the pandemic is open to the public in all countries [14].

In conclusion, the COVID-19 and the Spanish Flu are the greatest pandemics in the history of mankind with many similarities. However, there are also numerous specific features of each pandemic. This paper summarizes the results of this comparison. Based on the experiences from the Spanish Flu it may be expected that the COVID-19 might last until the end of 2021.

\section{Conflict of Interest}

The author declares no conflict of interests.

Keywords: Pandemics, Human influenza, Coronavirus, Severe acute respiratory syndrome

\section{References}

1. Di Wu, Wu T, Liu Q, Yang Z (2020) The SARS-CoV-2 outbreak: what we know. Int J Infect Dis 94: 44-48. [crossref]

2. Flecknoe D, Wakefield BC, Simmons A (2018) Plagues \& wars: the 'Spanish Flu' pandemic as a lesson from history. Med Confl Surviv 34: 61-68. 
3. Barry JM (2004) The Great Influenza: The Story of the Deadliest Pandemic in History. London: Penguin Books Ltd.

4. Radusin M (2012) The Spanish flu - part I: the first wave. Vojnosanit Pregl 69: 812817. [crossref]

5. Radusin M (2012) The Spanish flu - part II: the second and third wave. Vojnosanit Pregl 69: 917-927.

6. Morens DM, Taubenberger JK, Harvey HA, Matthew JM (2010) The 1918 Influenza Pandemic: Lessons for 2009 and the Future. Crit Care Med 38. [crossref]

7. Phan T (2020) Genetic diversity and evolution of SARS-CoV-2. Infect Genet Evol 81. [crossref]

8. Biggerstaff M, Cauchemez_S, Reed C, Manoj Gambhir, Lyn Finelli (2014) Estimates of the reproduction number for seasonal, pandemic, and zoonotic influenza: a systematic review of the literature. BMC Infect Dis 14. [crossref]
9. Peng PWH, Ho PL, Hota SS (2020) Outbreak of a new coronavirus: what anaesthetists should know. Br J Anaesth 124: 497-501. [crossref]

10. Rosenau MJ, Last JM Maxcy-Rosenau (1980) Preventive medicine and public health. New York: Appleton-Century-Crofts.

11. Giangreco G (2020) Case fatality rate analysis of Italian COVID-19 outbreak. J Med Virol 92: 919-923. [crossref]

12. Lauer SA, Grantz KH, Bi Q, Forrest K. Jones, Qulu Zheng, et al. (2020) The incubation period of coronavirus disease 2019 (COVID-19) from publicly reported confirmed cases: estimation and application. Ann Int Med.; 172: 577-582. [crossref]

13. Aligne CA (2016) Overcrowding and mortality during the influenza pandemic of 1918. Am J Public Health.; 106: 642-644 [crossref]

14. COVID19 coronavirus pandemic. Available at <https://www.worldometers.info/ coronavirus > Accessed November 5, 2020.

\section{Citation:}

Goran Belojevic (2020) COVID-19 and Spanish Flu Pandemics - Similarities and Differences. J Pharmacol Pharm Res Volume 3(3): 1-3. 